\title{
Backfill of a Mined-Out Gold Ore Deposit with the Cemented Rubber-Cord and Waste Rock Paste: Environmental Changes in Aqueous Media
}

\author{
Alexander Danilov ${ }^{1 *}$, Denis Korelskiy ${ }^{1}, V^{2}$ era Matveeva' ${ }^{1}$, Mika Horttanainen ${ }^{2}$ \\ 1 Saint-Petersburg Mining University, 2, 21st Line, 199106 Saint-Petersburg, Russia \\ 2 Lappeenranta - Lahti University of Technology, Yliopistonkatu 34, 53850 Lappeenranta, Finland \\ * Corresponding author's email: danilov_as@pers.spmi.ru
}

\begin{abstract}
Assessment of the dynamics of changes in the physical and chemical properties and morphological composition of the filling mixture as well as the identification of the elements capable of migrating into the environment is an important part of assessing the environmental efficiency of such an environmental measure during the filling of mined-out space of an ore deposit. During scientific research, the environmental safety mined-out space filling technology at the gold ore deposit by the mixture of rock waste, cement and crushed car tires was investigated. The authors carried out a set of laboratory studies and created a physical model of groundwater infiltration. Under laboratory conditions, this model allowed the experiment to evaluate the migration of elements and substances from the filling mixture into the environment to assess the risks of secondary pollution. The potential hazard of element migration from the backfill mixture into the environment was determined as a result of testing the backfill mixture on a bench with washing using the model solution that emits drainage water. During research, it was revealed that under the conditions of an ore deposit, the filling mixture components transformation would not lead to hazardous hydrochemical and hydrogeochemical areas or pollution stream formation.
\end{abstract}

Keywords: filling (backfill) mixture, physical and chemical properties, elements migration, waste utilization, mined-out space filling.

\section{INTRODUCTION}

During open pit mining or when mining ore with a low content of valuable constituents, large volumes of waste rock are formed, which are placed in surface storage in the mining area. Moreover, they contain a large amount of associated components $[1,2]$, which pose a threat in the process of long-term oxidation and weathering. It creates environmental issues in terms of land degradation, air and water pollution, etc. [3-6]. In addition to economic benefits, mining entails significant environmental impacts, including disruption to natural landscapes and ecosystems [7]. In order to mitigate these negative impacts and ensure a positive legacy for local communities, mining companies around the world generally need to pursue high-quality remediation and return the site to a state that supports consistent land use after mining [8].

Reclamation of old underground mines is required to reduce or eliminate the potential risk of mine subsidence and sinkhole formation, so there is a need to fill the void in a way that minimizes the impact of underground mining [4,9]. From this point of view, backfill is the most optimal way to utilize such waste, which also solves the problem of working out pillars, maintaining workings, and preventing subsidence of the earth's surface [5]. The material for filling can be various types of waste, from waste rock and tailings to ash, slag, and others obtained during the processing and use of extracted raw materials [9-14]. However, there are several problems in the reclamation of abandoned mines; for example, the material used to fill the voids of underground mines will interact 
with groundwater in the medium in long term, potentially causing the components to be leached from the backfill material into the groundwater system. The chemical migration process needs to be carefully assessed to ensure the quality of subterranean waters and groundwater in the area of closed deposits $[11,15]$.

With the development of cemented backfill technology in recent decades, the number of different types of mines that have been developed using the cemented backfill method has increased. Cemented backfill mining can effectively deal with solid waste generated from mining operations, reduce tailings stockpiling, and minimize secondary harm caused by contaminants. Moreover, during the backfill process, the surface environment can be protected so that the mine can achieve its sustainable development goals $[10,16]$.

If the ratio of the mixture components is studied, the solids content in the filling of a mine is usually from $60 \%$ to $80 \%$ by weight, depending on the various filling schemes used. Different volume fractions of solids included in the mine filler can alter its buoyancy and the apparent compressibility of the pore fluid, as well as its stiffness and permeability, which will ultimately affect the consolidation process [17]. This requires the consistency of the composition of the filling mixture with the flow rate of mine water. In this research, the consumption of water inflow into underground mine workings is expected to be insignificant, which makes it possible to reduce the cement content in the filling mixture, according to the results of the experiments carried out by the authors, it is the main source of leached pollutants.

In order to assess the suitability and potential environmental hazard of a backfill mixture planned for use in a gold deposit, the authors conducted a literature review of the backfill technologies as well as conducted laboratory experiments to assess the chemical composition and mobile forms of the elements using a complex of modern analysis methods. It is often noted that the hydrogeochemical models for predicting drainage quality from full-scale waste dumps may not be consistent with the data from small laboratory experiments of short duration. However, in a scale relationship study in laboratory and field experiments at the Antamina mine in Peru, the drainage mass loading ranged from $2 \mathrm{~kg}$ to $100,000 \mathrm{~kg}$ to simulate the observed rates and reproduce the geochemical composition of drainage at different scales. The study demonstrated that the scale dependence of geochemical velocities is largely explained by the surface area of chemically active minerals [18]. Thus, with a well-prepared and representative sample of filling materials, practical predictions of the quality of drainage can be made on the basis of readily available volumes under laboratory conditions.

The proposed projects for the reclamation of mining areas and the expected results of a longterm sustainable state are usually assessed by a set of «project completion criteria» $[8,19,20]$ - or in some studies by the integral «closure criteria» [21]. The four broadly applied principles governing mine closure are for an area to reach a state that:

- is physically / geotechnically stable and safe for humans and animals;

- is geochemically stable and safe from the point of view of pollution of environmental components;

- corresponds to the intended use of land after mining;

- is socially and environmentally sustainable, without the need for long-term active care [22].

In this study, as an assessment of the environmental risks of using the backfill mixture, the probability of an event of exceeding the standard concentration of each element in the model filtrate in a prolonged period was determined. All concentrations of water-soluble components of the backfill mixture turned out to be within the normative limits under conditions of a longer washout than under real conditions, which indicates the safety of using this backfill material for the environment.

\section{MATERIALS AND METHODS}

\section{Ore composition and backfilling technology}

During scientific research, the safety of the technology for filling the worked-out space of the gold ore deposit located in the Khabarovsk Territory, confined to the Albazin gold-bearing structure (hereinafter referred to as the deposit) was assessed. Within the Albazin structure, the Anfisinskaya, Olginskaya, and Ekaterininskaya ore-bearing zones are distinguished, which are bands of hydrothermally altered rocks associated with faults, and the thickness of the metasomatite zones varies from 20 to $100 \mathrm{~m}$. 
According to the composition of the rockforming ore, it comprises aluminosilicate, medium carbonate, according to the degree of oxidation, it is sulfide with insignificant traces of oxidation. The chemical composition of the deposited ore is presented in Table 1.

Gold is mainly associated with arsenopyrite, less often with quartz and carbonates. Gold is relatively low-grade (fineness 760 ), the mineral form of gold is native gold, microscopic, finely dispersed gold is present in the ore. The finished product of the company is a gold-bearing sulfide concentrate, which is transported to a hydrometallurgical plant for further processing.

For the development of reserves within the framework of underground mining, the use of a layered development system with backfilling of the goaf to hardening mixtures with the development of an extraction block in an ascending order is proposed (Figure 1). In this system, there are no supporting pillars to support the goaf. The enclosing rocks are maintained by filling the mined-out space with a hardening filling.

Work in the block begins with driving on the flanks of the block of layered ort-drives, in which layered drifts are intersected, and the stage-bystage shaping of the entire ore layer. After the complete mining of the layer, its complete filling is carried out with hardening mixtures, and - in the course of the cleaning works, while the filling mass is increasing- the required strength characteristics are moved to the adjacent block.

After mining off the layered drift for the entire length of the block, it is prepared for backfilling. For backfilling operations, the mouth of the drift is blocked by a bulkhead, where the backfill pipeline is inserted and filled with a hardening backfill mixture (Figure 2).

Table 1. Chemical composition of the deposited ore.

\begin{tabular}{|c|c|c|c|}
\hline Components & Content, \% & Components & Content, \% \\
\hline $\mathrm{SiO}_{2}$ & 65,1 & $\mathrm{Mn}$ & 0,11 \\
\hline $\mathrm{CaO}$ & 2,87 & $\mathrm{~Pb}$ & $<0,005$ \\
\hline $\mathrm{Al}_{2} \mathrm{O}_{3}$ & 12,9 & $\mathrm{Cu}$ & $<0,005$ \\
\hline $\mathrm{MgO}$ & 1,61 & $\mathrm{Zn}$ & $<0,005$ \\
\hline $\mathrm{TiO}_{2}$ & 0,42 & $\mathrm{Bi}$ & $<0,0005$ \\
\hline $\mathrm{Na}_{2} \mathrm{O}$ & 1,99 & $\mathrm{~S}$ total & 0,82 \\
\hline $\mathrm{K} 2 \mathrm{O}$ & 3,55 & $\mathrm{~S}$ sulf. & 0,8 \\
\hline $\mathrm{P}_{2} \mathrm{O}_{5}$ & 0,29 & $\mathrm{C}$ total. & 1,66 \\
\hline $\mathrm{Fe}$ & 2,46 & $\mathrm{C}$ org. & 0,29 \\
\hline $\mathrm{As}$ & 0,15 & $\mathrm{Se}$ & $<0,0005$ \\
\hline $\mathrm{Au}, \mathrm{g} / \mathrm{t}$ & 5,09 & $\mathrm{Te}$ & $<0,0005$ \\
\hline $\mathrm{Ag}, \mathrm{g} / \mathrm{t}$ & 2,3 & $\mathrm{Sb}$ & 0,0021 \\
\hline
\end{tabular}

According to the experience of filling works in similar fields, when filling the goaf with hardening mixtures to ensure the stability of adjacent layers, its strength should be about $1.5 \mathrm{MPa}$ [23]; according to the condition of the stability of the filling mass in the roof of the chamber, the strength of the filling is about $4.0 \mathrm{MPa}$ [12]. At the same time, there are technologies for filling the goaf with cementing materials with uniaxial compression strength less than 1.0 MPa [16,24]. According to the technical documentation for the object under consideration, to ensure the standard strength, the consumption of cement of a grade not lower than M100 will be 3.5-8 mass\% (from 75 to $160 \mathrm{~kg} / \mathrm{m}^{3}$ ), which will create a strength of over $4 \mathrm{MPa}$.

In the present field, as the main component of the filling mixture to be used, overburden (hereinafter - the crushed stone), they are formed in the extraction of gold ore. In order to use waste rock in the preparation of the backfill mixture, it is provided for its preliminary crushing to a size of $20 \mathrm{~mm}$ in a crushing and screening complex. In addition, within the framework of the study, it is proposed to consider the safety of the method for disposing of tires formed as a result of the production activities of the mining complex, as part of the filling mixture. Taking into account the volume of formation of overburden and waste rubber tires at the deposit, the share of $2.4 \%$ of the total volume of the filling mixture for burying the entire volume of this waste in the worked-out area was determined.

\section{Analysis methods}

Within the framework of scientific and practical research, the authors of the work carried out an assessment and forecast of a prolonged impact on water resources of a filling material consisting of a filling mixture (crushed stone + cement) and crushed spent tires by analyzing the gross composition of the mixture components, mobile forms of elements and leaching of mobile forms over time from a model sample.

For the chemical analysis of the components of the filling mixture, the following analysis methods were used:

- X-ray fluorescence spectrometry method;

- method of atomic emission spectrometry with inductively coupled plasma;

- method of atomic absorption spectrometry with flame and electrothermal atomization; 


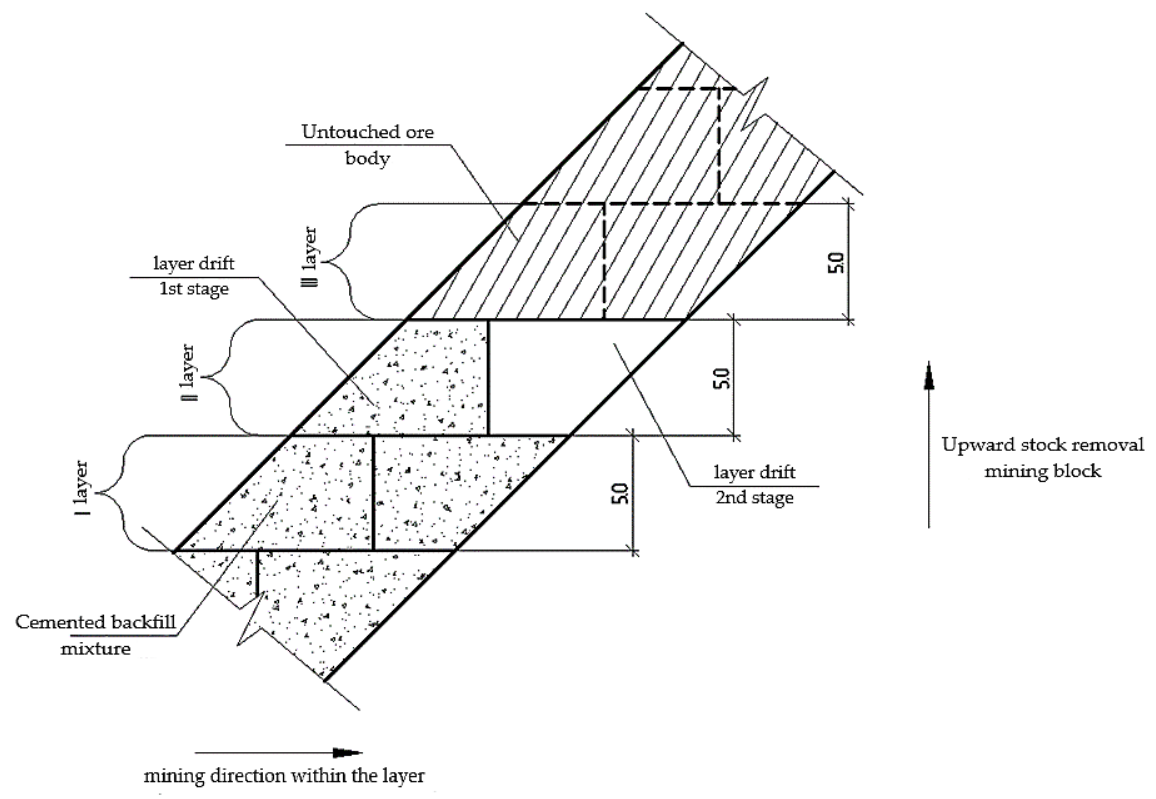

Figure 1. Layer mining scheme within the mining block.

- method of gas chromatography-mass spectrometry;

- infrared absorption method.

At the first stage of determining the elemental chemical composition of crushed stone and cement samples, semi-quantitative X-ray fluorescence analysis was used. An XRF-1800 (Shimadzu) sequential X-ray fluorescence spectrometer was used to implement this method in the laboratory.

The methods of atomic emission spectrometry with inductively coupled plasma and atomic absorption were used to determine the quantitative chemical composition of the studied samples and were implemented in an ICPE-9000 optical emission spectrometer (Shimadzu) and an AA-7000 (Shimadzu) absorption spectrometer, respectively.

For the analysis of organic compounds, the method of gas chromatography-mass spectrometry was used, which is based on a combination of two independent methods, i.e. chromatography and mass spectrometry. During the first stage, the mixture is separated into components, during the second, identification, determination of the structure of the substance, and quantitative analysis for the analysis in the laboratory, a GCMS-QP2010 Ultra (Shimadzu) gas chromatography mass spectrometer was used. The determination of

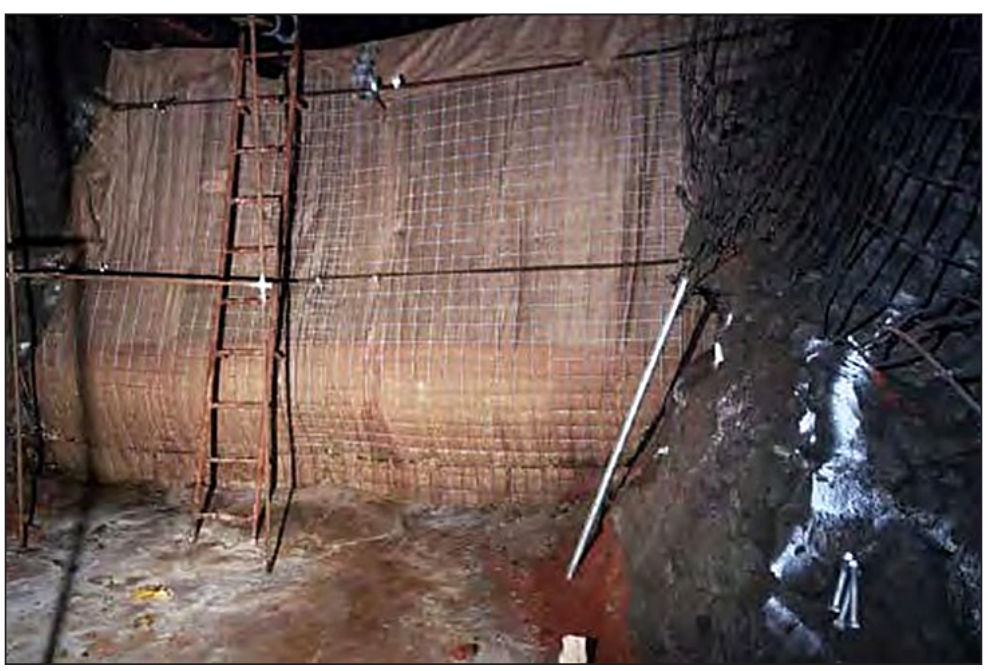

Figure 2. Jumper for retention tabs. 
such elements as $\mathrm{S}, \mathrm{C}, \mathrm{H}, \mathrm{N}$ was carried out using an analyzer from LECO, which uses an infrared absorption method.

In order to identify the mineral composition of the filling material components, the X-ray phase analysis was carried out on an XRD-6000 X-ray powder diffractometer with a HA1001 high-temperature chamber. Phases were searched using the JSPDC international card index.

\section{Sample preparation}

Before laboratory analysis, crushed stone and cement samples were averaged with the quartering method. Furthermore, the preparation of the crushed stone sample included its disintegration in a FRITSCH laboratory jaw crusher. Then, the crushed stone sample was reaveraged and a representative sample was taken for grinding to a powdery state in a Mill8000D laboratory ball mill mixer. Decomposition of crushed stone and cement samples to determine the total content of elements in the sample by atomic emission and atomic absorption spectrometry was carried out using a Multiwave 3000 microwave decomposition system.

For this purpose, a weighed portion of the analyzed sample weighing $0.5 \mathrm{~g}$ was placed in a fluoroplastic reaction cell, then reagents were added to it in accordance with the program shown in Table 2. Upon completion of the decomposition and cooling program, the resulting solutions were filtered through a «blue ribbon» filter into a volumetric flask by $50 \mathrm{~cm}^{3}$, while the inner walls of the reaction vessel and the filter with the precipitate were washed with deionized water and brought to the mark.

Decomposition of samples in determining the mobile form of an element was carried out in the following sequence. A portion of the analyzed sample weighing $2 \mathrm{~g}$ was placed in a glass beaker, then $10 \mathrm{~cm}^{3}$ of nitric acid with a molar concentration of $0.5 \mathrm{~mole} / \mathrm{dm}^{3}$ was added to it.
The solution of the weighed portion was mixed for 3 hours on a heated mixer at a temperature of $90^{\circ} \mathrm{C}$. Then, the sample was filtered through a paper filter into a $100 \mathrm{~cm}^{3}$ volumetric flask. The volume was brought to the mark with deionized water. The water extract was prepared with a solid: liquid ratio of $1: 5$. Crushed stone of $1-2 \mathrm{~mm}$ fraction was used for the analysis. A model solution represented by deionized water was used as a diluting liquid. Stirring was carried out on a magnetic stirrer for 8 hours.

Preparation of a sample of a rubber cord segment of a car tire consisted of crushing it using an electric jigsaw. The size of individual elements averaged $20-30 \mathrm{~mm}$. In order to determine the amount of water-soluble inorganic compounds in a car tire, a water extract was prepared using a model solution ( $\mathrm{pH} 7.5)$; the sample was mixed with the solution in a ratio of $1: 5$ at room temperature.

The determination of the content of watersoluble organic compounds in a sample of automobile tires was carried out in a water extract. In order to prepare it, the sample was crushed to $1-2 \mathrm{~mm}$, then $5 \mathrm{~g}$ of the sample were mixed with $7.5 \mathrm{ml}$ of deionized water in a bottle with a ground-in lid. The first contact of the sample with water was carried out for 5 days. Before analysis, the resulting solution was combined with a solvent (methylene chloride) in a 1: 1 ratio. The tire sample used was further tested to assess the migration of organic compounds over time. Before retesting, the sample was rinsed with deionized water and dried in the open air. Then, it was again placed in a bottle and filled with $7.5 \mathrm{ml}$ of deionized water. In order to study water-soluble organic compounds, the above-mentioned experiment was carried out in four repetitions. After the extraction, the extract was taken for semiquantitative analysis by gas chromatography mass spectrometry on a GCMS-QP2010 Ultra (Shimadzu) analyzer.

Table 2. Program for the bulk decomposition of crushed stone and cement samples in the Multiwave 3000 microwave sample preparation system.

\begin{tabular}{|c|c|c|c|c|c|}
\hline Stage & Sample weight, $g$ & Reagents & Volume, $\mathrm{ml}$ & Power, W & Time, $\min$ \\
\hline \multirow{4}{*}{1} & \multirow{5}{*}{0.5} & $\mathrm{HNO}_{3}$ concentrated & 5 & \multirow{4}{*}{1200} & \multirow{4}{*}{20} \\
\hline & & HF concentrated & 4 & & \\
\hline & & $\mathrm{HCl}$ concentrated & 1 & & \\
\hline & & $\mathrm{H}_{2} \mathrm{O}$ & 10 & & \\
\hline 2 & & $\mathrm{H}_{3} \mathrm{BO}_{3}(4 \%)$ & 20 & 1200 & 5 \\
\hline
\end{tabular}




\section{RESULTS AND DISCUSSION}

\section{Results of determining the gross composition of the mixture components}

The results of the gross analysis of the main components of the filling mixture are presented in Table 3.

Laboratory studies have shown that the main elements in the chemical composition of crushed stone are silicon and aluminum. The silicon content in terms of the oxide form reaches $63.7 \%$. At the same time, according to the data of phase analysis in the composition of crushed stone, silicon predominates in the form of quartz, which, according to the migration series in the weathering crust according to B.B. Polynova belongs to practically fixed elements. [25]. Quartz does not transform in the environment and does not pose a threat to it. In the second place is aluminum, which has a low migration capacity in natural waters and a tendency to form fairly stable complexes. Considering that the bulk of aluminum in the host rocks of the deposit is represented by aluminosilicates, the probability of the occurrence of aluminum-containing hydrogeochemical flows and pollution halos is extremely low. The mesocomponents of crushed stone include iron,

Table 3. Results of gross analysis of crushed stone and cement samples.

\begin{tabular}{|c|c|c|}
\hline \multirow{2}{*}{ Component } & \multicolumn{2}{|c|}{ Content, \% } \\
\cline { 2 - 3 } & Crushed stone & Cement \\
\hline $\mathrm{Al}_{2} \mathrm{O}_{3}$ & 17,9 & 5,6 \\
\hline $\mathrm{BaO}$ & 0,05 & 0,02 \\
\hline $\mathrm{CaO}$ & 2,4 & 56,6 \\
\hline $\mathrm{Fe}_{2} \mathrm{O}_{3}$ & 2,6 & 4,0 \\
\hline $\mathrm{K}_{2} \mathrm{O}$ & 3,0 & 0,9 \\
\hline $\mathrm{MgO}^{2}$ & 1,4 & 2,7 \\
\hline $\mathrm{MnO}_{2}$ & 0,06 & 0,08 \\
\hline $\mathrm{MoO}_{3}$ & 0,01 & 0,008 \\
\hline $\mathrm{Na}_{2} \mathrm{O}$ & 3,6 & 0,4 \\
\hline $\mathrm{SiO}_{2}$ & 63,7 & 20,8 \\
\hline $\mathrm{TiO}_{2}$ & 0,34 & 0,5 \\
\hline $\mathrm{ZnO}_{\mathrm{As}} \mathrm{O}$ & 0,001 & 0,01 \\
\hline $\mathrm{SrO}_{2}$ & 0,02 & 0,005 \\
\hline $\mathrm{P}_{2} \mathrm{O}_{5}$ & 0,01 & 0,02 \\
\hline $\mathrm{S}$ & 0,16 & - \\
\hline $\mathrm{C}$ & 0,26 & 1,5 \\
\hline $\mathrm{N}$ & 1,2 & - \\
\hline $\mathrm{H}$ & 0,05 & - \\
\hline & $<0,01$ & - \\
\hline
\end{tabular}

calcium, potassium, sodium, and magnesium. Calcium is represented by carbonate and silicate forms in the form of carbonates and plagioclases. These minerals do not dissolve in water, which makes it possible to speak unambiguously about the inertness of the material as a potential source of migratory calcium compounds. The predominant part of magnesium and potassium in the crushed stone sample under study is also in the silicate form of sericite and microcline, respectively. According to the results of diffractometric analysis, iron in crushed stone was revealed in several forms, namely: arsenopyrite, pyrite, goethite, hematite, magnetite, ilmenite. Given the amphotericity of iron oxides, it should be said that there is no potential interaction with aqueous solutions. Pyrite and arsenopyrite, as the predominant forms of iron in the sample, are also insoluble in water. Arsenic is among the most dangerous micro-impurities of crushed stone; however, in the composition of arsenopyrite, it does not pose a danger to the aquatic environment.

As for the gross analysis of a cement sample, the main elements (over 1\%) include calcium, silicon, aluminum, iron, magnesium, and sulfur (Table 3). The predominant compounds are calcium and silicon, which are presented mainly in the form of two- and three-calcium silicates. Aluminum is also predominantly found in silicate compounds, while magnesium and iron are found in oxide forms. In addition, iron is found in sulfur compounds. Considering the silicate matrix of the sample, it should be assumed that its components will not pose a serious threat to the aquatic environment.

\section{Results of determining the migratory forms of elements in the components of the mixture}

However, the gross content does not allow making unambiguous conclusions about the migration capacity of the components. The changes in physicochemical conditions can contribute to the geochemical transformations of individual components of crushed stone and cement in the composition of the filling material. In this regard, the next step in experimental work under laboratory conditions was to determine the mobile forms of the components of crushed stone and cement (Table 4).

The results of spectral analysis showed that the total content of mobile forms of crushed stone 
Table 4. Content of mobile forms of elements in the composition of crushed stone.

\begin{tabular}{|c|c|c|}
\hline \multirow{2}{*}{ Elements } & \multicolumn{2}{|c|}{ Content, $\mathrm{mg} / \mathrm{kg}$} \\
\cline { 2 - 3 } & Crushed stone & Cement \\
\hline $\mathrm{Al}$ & 2420 & 9,2 \\
\hline $\mathrm{Ba}$ & 78 & 22,6 \\
\hline $\mathrm{Ca}$ & 14358 & 61000 \\
\hline $\mathrm{Fe}$ & 12725 & - \\
\hline $\mathrm{K}$ & 738 & 1905 \\
\hline $\mathrm{Mg}$ & 5342 & - \\
\hline $\mathrm{Mn}$ & 304 & - \\
\hline $\mathrm{S}$ & 1558 & 5917 \\
\hline $\mathrm{Sr}$ & 85 & 120 \\
\hline $\mathrm{As}$ & 87 & - \\
\hline $\mathrm{Zn}$ & 3,2 & - \\
\hline $\mathrm{Mo}$ & - & 21,2 \\
\hline
\end{tabular}

components is $3.7 \%$ of the total content. The largest number of mobile forms was recorded for iron due to the dissolution of the main forms of rock-forming minerals in acid, as well as for calcium and magnesium, which are part of the main silicates. The content of mobile forms in cement is slightly higher than in the crushed stone sample and amounts to $6.9 \%$, while a significant part is represented by calcium, some compounds of which in the composition of cement are capable of reacting with nitric acid to form soluble compounds.

In the natural environment, the chance of emergence of conditions for the release of mobile forms of components under the condition of the formation of a solid monolith in the form of a hardened filling mixture is extremely low. For this reason, one of the most mobile water-soluble, forms of the component was studied, which represents the greatest danger to the surface and groundwater and at the same time is the most informative in assessing the environmental risks. The result of the analysis is presented in Table 5.

The table shows that the content of the elements found in the aqueous solution is extremely low. The total content of crushed stone components passed into the solution was $0.009 \%$. It should be noted that arsenic, one of the most dangerous elements in the composition of the studied rubble, was not detected in the aqueous solution, which confirms the previous assumption about the absence of interaction of arsenic compounds with water. As for the water-soluble forms in the composition of cement, their amount was $0.75 \%$ of the gross content, which is also a low indicator.
Table 5. Content of water-soluble components in a sample of crushed stone and cement.

\begin{tabular}{|c|c|c|}
\hline \multirow{2}{*}{ Elements } & \multicolumn{2}{|c|}{ Content, $\mathrm{mg} / \mathrm{kg}$} \\
\cline { 2 - 3 } & Crushed stone & Cement \\
\hline $\mathrm{Al}$ & 30,3 & 0,55 \\
\hline $\mathrm{Ba}$ & 0,5 & 0,705 \\
\hline $\mathrm{Ca}$ & 21,6 & 4185 \\
\hline $\mathrm{Fe}$ & 7,3 & - \\
\hline $\mathrm{K}$ & 12,1 & 770 \\
\hline $\mathrm{Mg}$ & 7,1 & - \\
\hline $\mathrm{Mn}$ & 0,02 & - \\
\hline $\mathrm{S}$ & 7,4 & 2540 \\
\hline $\mathrm{Sr}$ & 1,4 & 11,1 \\
\hline $\mathrm{Mo}$ & - & 11,4 \\
\hline
\end{tabular}

\section{Results of laboratory tests of rubber parts}

As noted earlier, it is proposed to use rubber cord waste in the filling mixture. Despite the low percentage of waste in the composition of the filling material, unlike the other two, it is a potential source of not only inorganic hydropollutants, but also organic ones. The results of the semiquantitative analysis of the water extract by gas chromatography mass spectrometry are presented in Table 6.

Table 6 shows that the main amount of organic water-soluble compounds is represented by the oxygen- and nitrogen-containing compounds of the aliphatic and aromatic series. On the whole, after the experiment was carried out in a fourfold repetition, the total amount of water-soluble organic compounds decreased 12.5 times from $0.005 \%$ to $0.0004 \%$. Increased migratory capacity was noted for the following organic compounds: hexanone-2, cyclohexylamine, aniline, benzyl chloride, N-cyclohexyl acetamide, phthalimide. As for the inorganic component, the analysis revealed such elements as calcium, potassium, iron, sulfur, and magnesium in the aqueous extract, while their total content was only $0.006 \%$.

\section{Desorption under static conditions}

The study of various forms of elements and compounds in the composition of individual components of the filling material made it possible to identify the hydro-pollutants potentially hazardous to the aquatic environment and became the basis for further experimental studies aimed at modeling the process of contacting the filling mixture with model aqueous solutions. 
Table 6. Results of a semiquantitative analysis of a water extract from a sample of a car tire by gas chromatography mass spectrometry (5 days)

\begin{tabular}{|c|c|c|c|l|}
\hline № & Exit time & Area, $\%$ & C, $\mathrm{mg} / \mathrm{g}$ & \multicolumn{1}{c|}{ Compound } \\
\hline 1 & 9,50 & 8,69 & 4,67 & hexanone-2 \\
\hline 2 & 12,18 & 0,66 & 0,35 & cyclohexylamine \\
\hline 3 & 13,20 & 1,26 & 0,68 & cyclohexanol \\
\hline 4 & 13,55 & 5,96 & 3,20 & cyclohexanone \\
\hline 5 & 15,33 & 0,38 & 0,21 & cyclohexyl isocyanate \\
\hline 6 & 15,42 & 1,82 & 0,98 & aniline \\
\hline 7 & 16,35 & 0,50 & 0,27 & glycerol \\
\hline 8 & 18,69 & 2,69 & 1,45 & 1 - (2-Butoxyethoxy) ethanol (ethylene glycol monobutyl ether) \\
\hline 9 & 19,58 & 1,36 & 0,73 & 2,4 - diethyl - 1,3,2 - dioxaborolane \\
\hline 10 & 19,65 & 4,96 & 2,67 & benzothiazole \\
\hline 11 & 20,91 & 9,46 & 5,09 & N-cyclohexylformamide \\
\hline 12 & 21,21 & 13,81 & 7,42 & N-cyclohexyl acetamide \\
\hline 13 & 21,94 & 43,34 & 23,29 & dicyclohexylamine \\
\hline 14 & 23,76 & 5,11 & 2,74 & phthalimide \\
\hline & Total & 100 & 53,74 & \\
\hline
\end{tabular}

At the initial stage, experiments were carried out under static and dynamic conditions for each of the components of the mixture separately. For the research, a model solution with a $\mathrm{pH}$ value of 7.5 was used, which corresponds to the $\mathrm{pH}$ of the groundwater sampled from the wells near the considered field. In order to simulate the process of contacting the components of the filling mixture and assess the behavior of its individual components in the solution, the preliminarily crushed sample was placed in a container with a solution in a ratio of 1: 5. The experimental conditions are shown in Table 7.

In the first minutes of contact, stirring was carried out, and then the test load remained at rest for 40 days. Sampling for analysis was carried out daily. The results of the study showed that for the crushed stone sample at the final stage of the experiment, the concentration in the solution of such elements as calcium, potassium, magnesium, sulfur, strontium, manganese became constant, which indicates the complete release of mobile forms of elements under the considered conditions. In turn, for aluminum and iron, the maximum concentrations were observed in the first hours of contact, and then the concentration of each of the elements in the solution decreased, which was caused by such processes as precipitation, sorption, and coagulations characteristics of these elements. As for carrying out a similar experiment for a cement sample, the concentrations of the detected elements in the solution were maximum during the first hours of the experiment. Furthermore, due to the finely dispersed composition of the sample, the reverse process was observed, i.e. the sorption of dissolved components on solid particles, followed by cementation of the sample. The results of the assessment of the migration activity of the components of the spent automobile tire showed a gradual increase during the experiment in iron and manganese that is associated with the process of corrosion of the cord, which, in principle, is the main supplier of inorganic soluble compounds. The release of sulfur from the sample can be explained by its widespread use in the vulcanization process. In addition, significant calcium contents were recorded in the model solution at the level of $20-25 \mathrm{mg} / \mathrm{dm}^{3}$. Its main sources include the calcium-containing deicing coatings, as well as the waste rock used in the dumping of internal roads.

Table 7. Conditions for conducting experimental studies under static conditions.

\begin{tabular}{|l|c|c|c|c|c|}
\hline \multicolumn{1}{|c|}{ Component name } & $\begin{array}{c}\text { Component size, } \\
\mathrm{mm}\end{array}$ & $\begin{array}{c}\text { Model solution } \\
\text { volume, } \mathrm{dm}^{3}\end{array}$ & $\begin{array}{c}\text { Component } \\
\text { weight, } \mathrm{g}\end{array}$ & $\begin{array}{c}\mathrm{pH} \text { of the model } \\
\text { solution }\end{array}$ & $\begin{array}{c}\text { Ambient } \\
\text { temperature, } 0^{\circ} \mathrm{C}\end{array}$ \\
\cline { 1 - 2 } Crushed stone & $1-2$ & & & & \\
\cline { 1 - 2 } Rubber cord waste (car tire) & $20-30$ & 1 & 200 & 7,5 & 20 \\
\cline { 1 - 2 } Cement & - & & & \\
\hline
\end{tabular}




\section{Desorption under dynamic conditions}

In order to implement the experiment under dynamic conditions, a laboratory column was used. Crushed stone, which is the main component of the filling mixture, was used as column filler. Before loading, the initial sample of crushed stone was disintegrated in a laboratory jaw crusher to a particle size of $1-2 \mathrm{~mm}$. As a model, similar to the previous experiments, a water solution with an artificially created $\mathrm{pH}$ value of 7.5 was used. The flow rate of the model solution throughout the experiment was $5 \mathrm{~cm}^{3} / \mathrm{min}$, and its constancy was maintained using a pump. The total mass of the load was $174 \mathrm{~g}$. The equipment installation for the experiment is shown in Figure 3.

In total, the experiment lasted 40 days. The total amount of the model solution passed through the column was 175 liters. Figure 4 shows the curves of migration of chemical elements from the column over time.

As can be seen from Figure 4, for most of the mobile components of the sample, with an increase in the volume of the passed solution, their content in the solution gradually decreased. The mass and fraction of the sample components that passed into the solution over the entire period of the experiment are presented in Table 8.

\section{Enlarged laboratory tests}

At the final stage, expanded laboratory tests were carried out at a three-stage water purification setup. This installation allows conducting experiments with the simultaneous use of up to four types of charges in separate columns. In order to carry out the expanded laboratory tests, one of the columns of the laboratory setup with a diameter of $200 \mathrm{~mm}$ was filled with crushed filling mixture (Figure 5).

The flow rate of the model solution throughout the experiment was $30 \mathrm{dm}^{3} / \mathrm{h}$. The volume of the model solution passed through each of the charges was $1500 \mathrm{dm}^{3}$. Due to the fact that the hydrogeological conditions of the field development are simple and the maximum inflow of water will be $146,000 \mathrm{dm}^{3} / \mathrm{h}$, whereas the minimum $-17,000 \mathrm{~m}^{3} / \mathrm{h}$, the experimental data will give a greater saturation of filtration water with water-soluble forms of substances, which will be taken into account when assessing the environmental hazard. In accordance with the selected recipe, two backfill solutions were prepared with the maximum (8\%) and minimum (3.5\%) cement contents.

After solidification, the sample was crushed to a size of $2-3 \mathrm{~cm}$ and loaded into the column. According to the main parameters, the used model solution corresponded to the composition of the underground waters of the ore deposit. The results of the experiment, taking into account the concentrations of the studied elements in the initial model solution, are presented in Tables 9 and 10 .

The results presented in Tables 9 and 10 show that the main component migrating into the solution is $\mathrm{Ca}$. At the same time, higher contents are noted in the load with lower cement content. Therefore, stronger carburizing of the mixture prevents calcium leaching from the sample. At
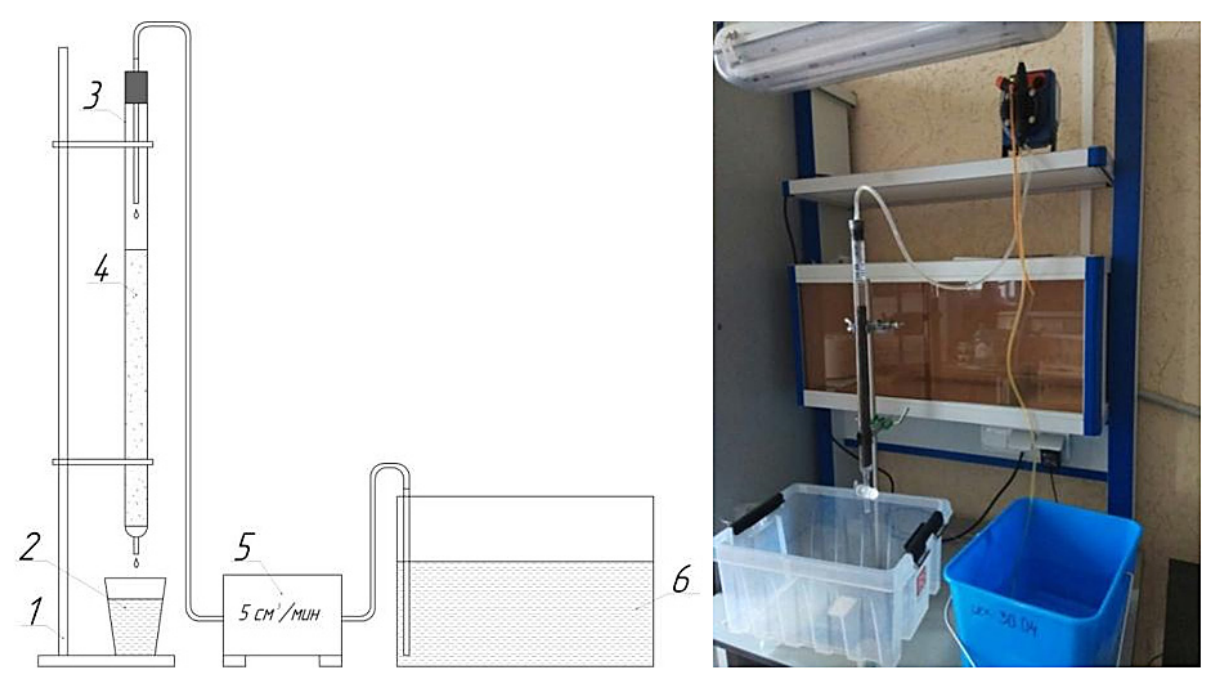

Figure 3. Installation of an experiment t on the leaching of components from a crushed stone sample under dynamic conditions: 1 - tripod; 2 - model solution after passing through the column; 3 - laboratory column; 4 - crushed stone with a size of 1-2 mm; 5 - pump; 6 - the original model solution. 
a)
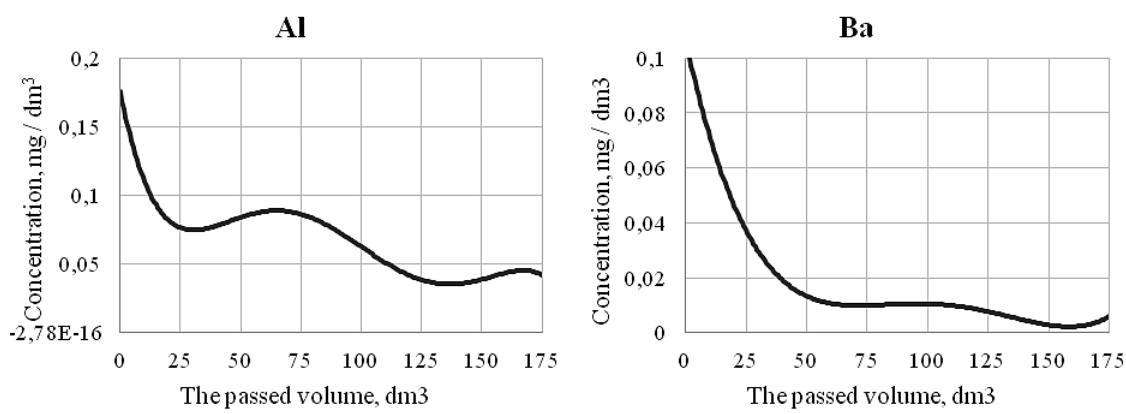

Ca
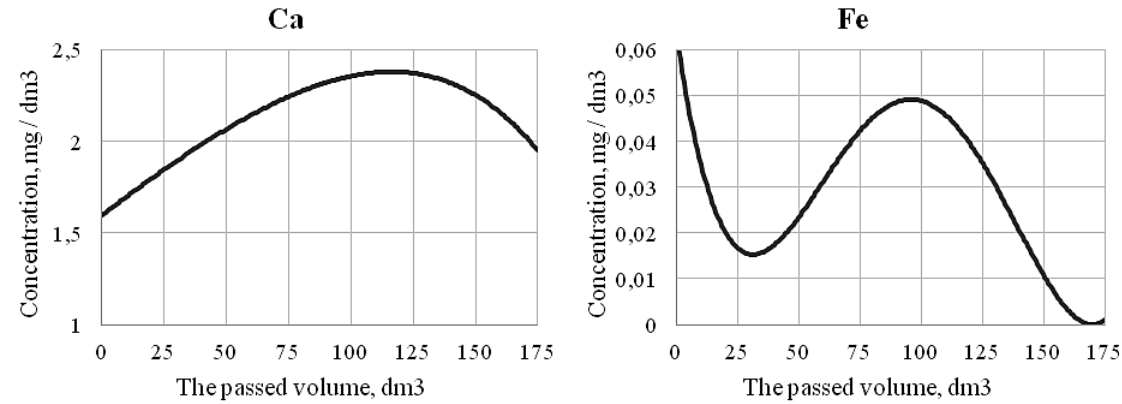

b)
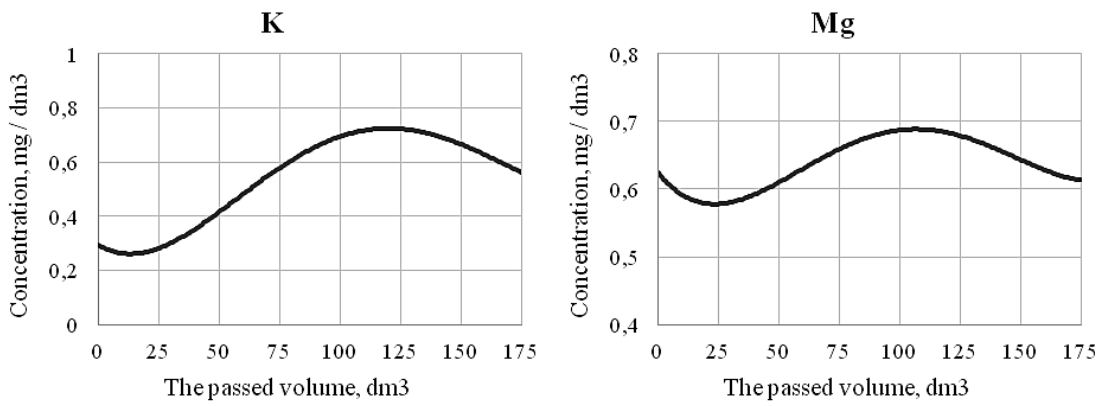

S
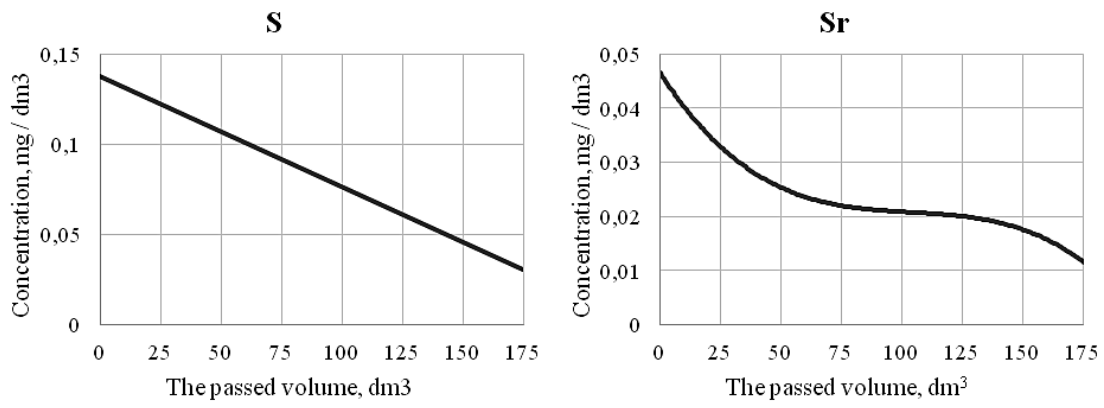

Figure 4. Curves of migration of chemical elements from a crushed stone sample under dynamic conditions

the same time, Mo was found in the solution that passed through the load with a cement content of $8 \%$. This is due to the fact that the mobile and water-soluble forms of Mo are present in the cement, and its increase in the load leads to a natural increase in the concentration in the model solution that has passed through the column.

The resulting filtrate of the filling mixture was analyzed for the content of organic compounds. The results of the analysis showed that no organic compounds were found in the sample. The content of each of the organic compounds identified during the study of the water-soluble forms of the components of the spent car tire turned out to be below the detection limit of the modern GCMSQP2010 Ultra analyzer $\left(<10 \mu \mathrm{g} / \mathrm{dm}^{3}\right)$.

In order to intensify the process of leaching the components of the filling mixture, a model solution was poured into the column with loading, after which the column was dismantled from the stand and shaken manually (Figure 6).

Then, the column was installed back and started again. As a result of launching the stand, no sharp change in the electrical conductivity 
Table 8. Mass and fraction of components of the crushed stone sample that migrated into the solution under dynamic conditions for the entire period of the experiment

\begin{tabular}{|c|c|c|}
\hline Element & $\begin{array}{c}\text { The mass of the } \\
\text { crushed stone } \\
\text { component passed } \\
\text { into the solution, } \mathrm{mg}\end{array}$ & $\begin{array}{c}\text { The proportion of the } \\
\text { component in the total } \\
\text { content in the sample, } \%\end{array}$ \\
\hline $\mathrm{Al}$ & 12 & 0,07 \\
\hline $\mathrm{Ba}$ & 3 & 4,83 \\
\hline $\mathrm{Ca}$ & 381 & 12,55 \\
\hline $\mathrm{Fe}$ & 5 & 0,16 \\
\hline $\mathrm{K}$ & 95 & 2,18 \\
\hline $\mathrm{Mg}$ & 113 & 7,83 \\
\hline $\mathrm{S}$ & 15 & 3,39 \\
\hline $\mathrm{Sr}$ & 4 & 41,39 \\
\hline
\end{tabular}

of the solution passed through the column was observed, which indicates that the dynamics of leaching after shaking the column was preserved.

Assessment of the environmental risk when using the studied material of the backfill, taking into account the available initial data and modeling results, as well as taking into account the tasks of the research work, is reduced to assessing the risk of water pollution. In addition to groundwater, it is necessary to consider surface waters, since during the laying of the worked-out space, a certain amount of leached components will be transported by the drainage system with mine water to surface water bodies.

As a result of the assessment of the «worst case» scenario with the minimum intensity of water pumping through the model of the filling array, the concentrations of elements in the filtrate were obtained, presented in Table 11.

\section{Environmental risk assessment}

In order to assess environmental risk, it is customary to use the following well-known formula:

$$
R=\sum_{i=1}^{n} P_{i} W_{i}
$$

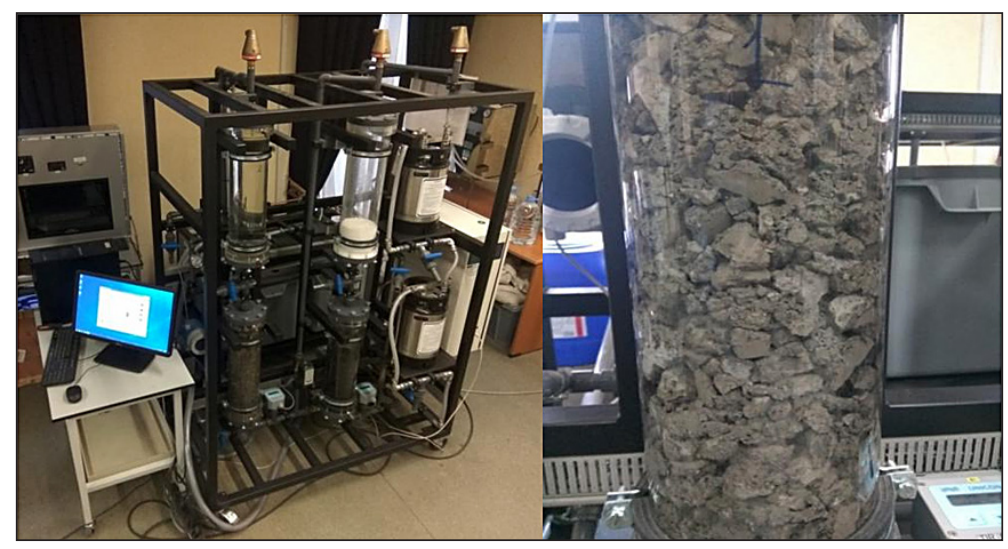

Figure 5. Curves of migration of chemical elements from a crushed stone sample under dynamic conditions.

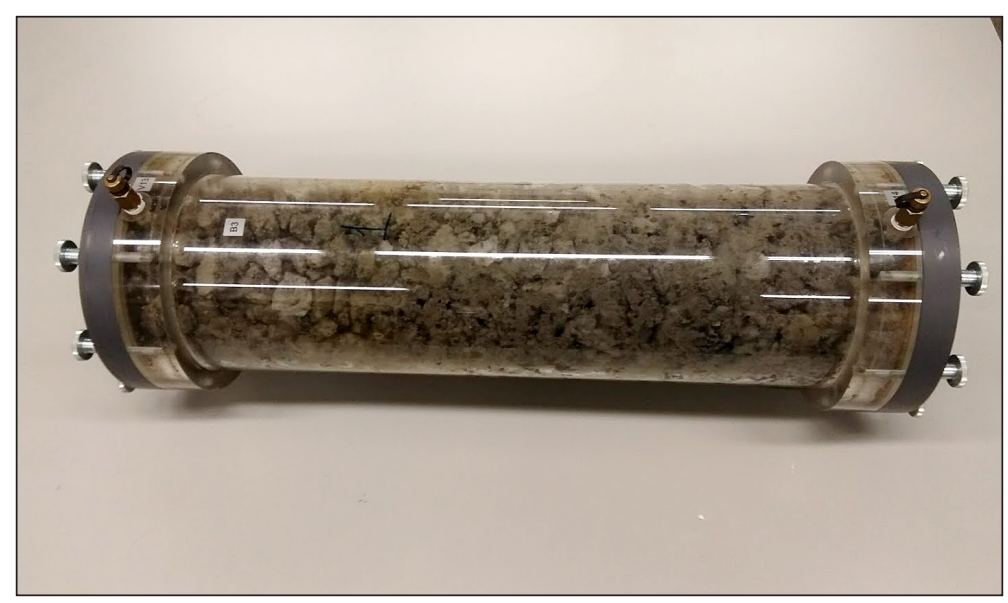

Figure 6. Dismantled column with loading. 
Table 9. Results of expanded laboratory tests using a filling mixture with cement content of $8 \%$.

\begin{tabular}{|l|c|c|c|c|c|c|c|}
\hline \multicolumn{1}{|c|}{ Element } & $\mathrm{Al}$ & $\mathrm{Ba}$ & $\mathrm{Ca}$ & $\mathrm{K}$ & $\mathrm{Mo}$ & $\mathrm{S}$ & $\mathrm{Sr}$ \\
\hline Content of elements in the load, $\mathrm{mg}$ & 836493 & 3866 & 471773 & 229431 & 1406 & 35402 & 627 \\
\hline $\begin{array}{l}\text { Component mass transferred into solution } \\
\text { during the experiment, } \mathrm{mg}\end{array}$ & 52 & 26 & 34260 & 1027 & 20 & 1211 & 178 \\
\hline $\begin{array}{l}\text { The percentage of the component in the } \\
\text { solution from the gross content in the load, } \%\end{array}$ & 0,006 & 0,664 & 7,262 & 0,448 & 1,453 & 3,419 & 28,388 \\
\hline
\end{tabular}

Table 10. Results of expanded laboratory tests using a filling mixture with cement content of $3.5 \%$.

\begin{tabular}{|l|c|c|c|c|c|c|}
\hline \multicolumn{1}{|c|}{ Element } & Al & Ba & Ca & K & S & Sr \\
\hline Content of elements in the load, mg & 1102349 & 5024 & 211061 & 301752 & 31350 & 687 \\
\hline $\begin{array}{l}\text { Component mass transferred into solution } \\
\text { during the experiment, mg }\end{array}$ & 297 & 41 & 25289 & 583 & 4873 & 105 \\
\hline $\begin{array}{l}\text { The percentage of the component in the } \\
\text { solution from the gross content in the load,\% }\end{array}$ & 0,027 & 0,807 & 11,982 & 0,193 & 15,543 & 15,285 \\
\hline
\end{tabular}

Table 11. Average content of elements in the filtrate after pumping the model solution through the filling array model according to the «worst case» scenario.

\begin{tabular}{|l|c|c|c|c|c|c|c|}
\hline \multirow{2}{*}{ Water sample } & \multicolumn{7}{|c|}{ Average concentration of an element in the filtrate, $\mathrm{mg} / \mathrm{dm} 3$} \\
\cline { 2 - 9 } & $\mathrm{Al}$ & $\mathrm{Ba}$ & $\mathrm{Ca}$ & $\mathrm{K}$ & $\mathrm{SO}_{4}{ }^{2-}$ & $\mathrm{Sr}$ & $\mathrm{Mo}$ \\
\cline { 2 - 9 } & 1 & 2 & 3 & 4 & 5 & 6 & 7 \\
\hline $\begin{array}{l}\text { Content in the filtrate after pumping the model } \\
\text { solution through the model of the filling block }\end{array}$ & 0,03 & 0,027 & 16,86 & 0,39 & 9,75 & 0,07 & - \\
\hline $\begin{array}{l}\text { Maximum permissible concentration for water } \\
\text { bodies of fishery significance, } \mathrm{mg} / \mathrm{dm}^{3}\end{array}$ & 0,04 & 0,74 & 180,0 & 50,0 & 100,00 & 0,40 & 0,001 \\
\hline
\end{tabular}

where: $P_{i}-$ the probability of exceeding the concentration of an element in excess of the standard;

$W_{i}$ - costs of eliminating the consequences of exceeding the standard;

$i$ - the ordinal number of the element.

In order calculate the probability of an event of exceeding the standard concentration of the $\mathrm{i}$-th element in water, in a prolonged period $\Delta \mathrm{t}$, one can use the formula:

$$
P_{i}(\Delta t)=1-\exp \left(-\lambda_{i} \Delta t\right),
$$

where: $\lambda_{i}-$ the frequency of realizations of the event of exceeding the normative concentration of the $i$ element, calculated by the formula: $\lambda_{i}=k_{i} / \Delta T$,

$k_{i}$ - the number of hazardous events (exceeding the normative concentration of the $i$ element) for the observation interval $\Delta \mathrm{T}[26]$.

The results of laboratory experimental studies on the model of the filling mass showed that for all detected components, in accordance with the regulatory documents of the Russian
Federation, taking into account the quantitative and qualitative characteristics of mine waters, the characteristics of water bodies (sewage receivers) and treatment facilities of mine waters of the enterprise, -- the number of hazardous phenomena $\mathrm{k}=0$. Thus, using formulas (1) - (2), when assessing the environmental risk of applying the studied backfill mixture for backfilling the mined-out space of the mine, the value $\mathrm{R}=0$ is obtained.

\section{CONCLUSIONS}

During the research work, a significant amount of laboratory research was carried out using a complex of modern methods of analysis and an expanded experiment on a physical model of a filling mass, represented by a filling mixture of crushed stone, cement and elements of used automobile tires, which made it possible to solve the following scientific and practical problems:

- identifying the chemical elements and substances (compounds) formed during the splitting (destruction) of waste tires and mineral components of the filling mixture; 
- creating a physical model, which made it possible, in a laboratory experiment, to evaluate the movement (migration) of elements and substances from the filling mixture into the environment when washed out by groundwater;

- identifying the potential dangers of migration of elements from the backfill into the environment when implementing decisions on backfilling the underground mined space of the mine with a backfill mixture with used covers, on the basis of the data obtained as a result of laboratory analyses and experimental studies of the model.

As a result of the conducted theoretical, laboratory, and expanded experimental studies, the following results were obtained:

1. The main potential type of impact on the environment when organizing the backfill of the mine goaf with the mixture under study is the leaching of organic and inorganic compounds from the backfill material upon contact with water and the formation of a flow of polluted water, which justifies the need for laboratory studies of the mixture components carried out by the authors to assess the risks of secondary pollution.

2. Investigation of the chemical and phase compositions of crushed stone as the main component of the filling mixture showed that silicon and aluminum predominate in the waste, which, like most other components, occurs in a hardly soluble silicate matrix. This matrix prevents the release of waste components into the solution, which is confirmed by the low content of mobile $(3.7 \%)$ and water-soluble $(0.009 \%)$ forms.

3. In the composition of the cement used in the filling mixture, calcium and silicon, which are represented by two- and three-calcium silicates, are the predominant compounds. The content of mobile form is $6.9 \%$, and the content of water-soluble form is $0.75 \%$. The main component of the solutions after leaching a cement sample is calcium.

4. During the study of organic water-soluble components of rubber cord waste, oxygen and nitrogen-containing compounds of the aliphatic and aromatic series in the amount of $0.005 \%$ were recorded in the solution. As for the inorganic component, the analysis revealed such elements as calcium, potassium, iron, sulfur, and magnesium in the aqueous extract, while their total content was $0.006 \%$.
5. During expanded laboratory tests of the backfill mixture on the bench with washing with a model solution emitting drainage water, no organic compounds were found in the filtrate. This confirms the safety of the proposed technology for joint disposal of mining waste and waste tires in the worked-out area.

6. Large-scale laboratory tests have shown that when the content of cement in the filling mixture is in an amount of $3.5 \%$ and $8 \%$ and when the waste material is crushed into pieces with a size of $20-30 \mathrm{~mm}$, active migration into the calcium solution is noted. At the same time, lower grades were noted in the load with a high cement content, which is associated with a more durable carburizing of the mixture, which prevents leaching.

Thus, it can be concluded that the use of the filling mixture according to the presented recipe under real conditions in the considered field, the transformation of the mixture components will not pose an environmental hazard to the aquatic environment of the production region, since the probability of exceeding the standard concentration tends to zero.

\section{Acknowledgments}

The research was carried out with the support of core shared facilities of Saint-Petersburg Mining University.

\section{REFERENCES}

1. Sizyakov, V.M., Nazarov, Y.P., Brichkin, V.N., Sizyakova, E.V. 2016. Processing of aged dumped tailings of apatite-nepheline ores flotation. Obogashchenie Rud, (2), 33-39. doi: 10.17580/or.2016.02.06

2. Pashkevich, M.A., Petrova, T.A. 2016. Technology of artificial deposit preservation at the kursk magnetic anomaly. Journal of Ecological Engineering, 17(4), 11-16. doi: 10.12911/22998993/64565

3. Amos, R.T., Blowes, D.W., Bailey, B.L., Sego, D.C., Smith, L., \& Ritchie, A.I.M. 2015. Wasterock hydrogeology and geochemistry. Applied Geochemistry, 57, 140-156. https://doi.org/https://doi. org/10.1016/j.apgeochem.2014.06.020

4. B.S. Choudhary, S. Kumar 2013. Underground void filling by cemented mill tailings. Int J Min Sci Technol, 23(6), 893-900 DOI:10.1016/j. ijmst.2013.11.003

5. Pashkevich, M.A., Petrova, T.A. 2017. Technogenic 
impact of sulphide-containing wastes produced by ore mining and processing at the ozernoe deposit: Investigation and forecast. Journal of Ecological Engineering 18(6), 127-133 https://doi. org/10.12911/22998993/76700

6. Nguyen, K.L., Gabov, V.V., Zadkov, D.A. 2018. Improvement of drum shearer coal loading performance. Eurasian Mining, 2018(2), 22-25. doi: 10.17580/em.2018.02.06

7. Litvinenko, V.S. Digital Economy as a Factor in the Technological Development of the Mineral Sector (2020) Natural Resources Research, 29(3), 1521-1541 doi: 10.1007/s11053-019-09568-(4)

8. Rosa, Josianne Cláudia Sales, Sánchez, L.E., \& Morrison-Saunders, A. (2018). Getting to 'agreed' post-mining land use - an ecosystem services approach. Impact Assessment and Project Appraisal, 36(3), 220-229. https://doi.org/10.1080/14615517 .2018 .1445175

9. Golik V.I., Dmitrak Yu.V., Komashchenko V.I., Kachurin N.M. (2020) Management of hard-ening mixtures properties when stowingmining sitesof ore deposits.JournalofMining Institute, 243, 285-292. DOI: 10.31897/PMI.2020.3.285

10. Franks, D.M., Boger, D.V, Côte, C.M., \& Mulligan, D.R. (2011). Sustainable development principles for the disposal of mining and mineral processing wastes. Resources Policy, 36(2), 114-122. https://doi.org/ https://doi.org/10.1016/j.resourpol.2010.12.001

11. Baotang Shen, Brett Poulsen, Xun Luo, Johnny Qin, Ramesh Thiruvenkatachari, Yi Duan (2017). Remediation and monitoring of abandoned mines. International Journal of Mining Science and Technology, 27(5), 803-811, https://doi.org/10.1016/j. ijmst.2017.07.026

12. Zhiqiang Yang, Shuhua Zhai, Qian Gao, Maohui Li. 2015. Stability analysis of large-scale stope using stage subsequent filling mining method in Sijiaying iron mine. Journal of Rock Mechanics and Geotechnical Engineering, 7(1), 87-94, https://doi. org/10.1016/j.jrmge.2014.11.003

13. Wentao Lan, Aixiang Wu, Ping Yu, 2020. Development of a new controlled low strength filling material from the activation of copper slag: Influencing factors and mechanism analysis. Journal of Cleaner Production, 246, https://doi.org/10.1016/j. jclepro.2019.119060

14. Zuev, B.Y., Zubov, V.P., Fedorov, A.S Application prospects for models of equivalent materials in studies of geomechanical processes in underground mining of solid minerals. Eurasian Mining 2019(1), 8-12. DOI: 10.17580/em.2019.01.02

15. Jarsjö, J.; Chalov, S.R.; Pietroń, J.; Alekseenko, A.V.; Thorslund, J. 2017. Patterns of Soil Contamination, Erosion and River Loading of Metals in a Gold Mining Region of Northern Mongolia.
Regional Environmental Change, 17, 1991-2005, doi:10.1007/s10113-017-1169-6

16. Deng, D. Q., Liu, L., Yao, Z. L., Song, K. I.-I. L., \& Lao, D. Z. (2017). A practice of ultra-fine tailings disposal as filling material in a gold mine. Journal of Environmental Management, 196, 100-109. https://doi.org/https://doi.org/10.1016/j. jenvman.2017.02.056

17. Lu, G.-D., Yang, X.-G., Qi, S.-C., Fan, G., \& Zhou, J.-W. (2020). Coupled chemo-hydro-mechanical effects in one-dimensional accretion of cemented mine fills. Engineering Geology, 267, 105495. https://doi. org/https://doi.org/10.1016/j.enggeo.2020.105495

18. Vriens, B., Seigneur, N., Mayer, K. U., \& Beckie, R. D. (2020). Scale dependence of effective geochemical rates in weathering mine waste rock. Journal of Contaminant Hydrology, 234, 103699. https://doi. org/https://doi.org/10.1016/j.jconhyd.2020.103699

19. Rosa, Josianne Claudia Sales, Geneletti, D., Morrison-Saunders, A., Sánchez, L. E., \& Hughes, M. (2020). To what extent can mine rehabilitation restore recreational use of forest land? Learning from 50 years of practice in southwest Australia. Land Use Policy, 90, 104290. https://doi.org/https://doi. org/10.1016/j.landusepol.2019.104290

20. Fomin, S.I. (2016) Foundations for technical solutions in organizing excavation of open ore pits. Zapiski Gornogo institute, 221, 644-650. DOI 10.18454/PMI.2016.5.644

21. Bollhöfer, A., Beraldo, A., Pfitzner, K., Esparon, A., \& Doering, C. (2014). Determining a pre-mining radiological baseline from historic airborne gamma surveys: A case study. Science of The Total Environment, 468-469, 764-773. https://doi.org/https://doi. org/10.1016/j.scitotenv.2013.09.001

22. Manero, A., Kragt, M., Standish, R., Miller, B., Jasper, D., Boggs, G., \& Young, R. (2020). A framework for developing completion criteria for mine closure and rehabilitation. Journal of Environmental Management, 273, 111078. https://doi.org/https:// doi.org/10.1016/j.jenvman.2020.111078

23. Adigamov, A.E. (2008) A mathematical method for determining the standard strength of a fill taking into account mining and geological factors, GIAB. 10, 204-206

24.Zuev, B.Y., Zubov, V.P., Smychnik, A.D. 2019. Determination of static and dynamic stresses in physical models of layered and block rock masses. Gornyi Zhurnal, (7), 61-66. DOI: 10.17580/ gzh.2019.07.02

25. Perelman A.I. (1983) Geochemistry of natural waters, publishing house "Nauka" Moscow, $154 \mathrm{p}$.

26. Jorgensen, S.E., Fath, B.D. (2011) Ecotoxicological Models. Developments in Environmental Modelling, 23, 229-290. https://doi.org/10.1016/ B978-0-444-53567-2.00008-9. 